\title{
REVIEWS
}

DOI: 10.23888/humJ20191256-289

\section{ANNOTATIONS OF FINAL QUALIFYING WORKS OF STUDENTS OF THE FACULTY OF CLINICAL PSYCHOLOGY IN 2019}

\section{Yevgenia V. Alekseeva \\ "Coping-Strategies and Mechanisms of Psychological Defense in Sickly Pri- mary School-Aged Children" \\ Research adviser - Grand PhD in Medical sciences, professor B.Yu. Volodin}

Aim: study of mechanisms of psychological defense and of coping-strategies in sickly primary school-aged children.

\section{Results;}

1) Sickly children use more primitive mechanisms of psychological defense, namely denial and squeezing out used by more mature children.

2) Sickly children often discuss the complicated situation with themselves and do not tend to discuss it with others, they try to sooth themselves independently, they are not characterized by affective and aggressive resolution of anxiety, in contrast to healthy children. All this promotes repression of emotional tension in stressful situations which is characteristic of psychosomatic diseases.

3) Sickly children are less oriented towards social interaction, since they commonly keep away both from a teacher and from an adult person on the whole; they to a lesser extent tend to socialize in large groups of children than healthy children, they to a more extent tend to stay alone and on the whole go through a complicated for them situation in a more depressed emotional condition than their healthy peers. 


\section{Yana V. Babonova}

"Peculiarities of Self-Regulation and Health Saving Behavior of Patients with Type II Diabetes Mellitus"

\section{Research adviser - PhD in Psychological sciences, senior lecturer A.G.}

Faustova

Aim: study of personal predictors of self-regulation and health saving behavior.

Results: hypotheses of study were partially confirmed. Hypothesis of relationship between health saving behavior and personality traits (neuroticism) in patients with type II diabetes mellitus was confirmed. The hypothesis of existence of interrelation between self-regulation and health saving be continued in other studies.

\section{Kirill S. Burmistrov}

"Peculiarities of Emotional-Volition Sphere of Teenagers Taking Alcohol with Bad Consequences"

Research advisor - PhD in Medical sciences, associate professor A.K. Afonina

Aim: identification of peculiarities of emotional-volition sphere of teenagers taking alcohol with bad consequences.

\section{Results:}

1. Teenagers taking alcohol with bad consequences, have a passion for selfdemonstration, they more often than other teenagers strive for fame and success in front of other people.

2. Teenagers taking alcohol with bad consequences, are in most cases passive in some kind of activity. Their passiveness is mostly associated with low, depressed mood.

3. Aggressiveness of teenagers taking alcohol with bad consequences, is mostly associated with low depressed mood and is of high level. 
4. Emotional excitability of teenagers taking alcohol with bad consequences, stays at a high level, but is not linked with increase in aggressiveness.

5. Volitional regulation of teenagers taking alcohol with bad consequences, is characterized by disorders in target setting, self-control and self-organization.

\section{Ekaterina A. Golub}

\section{"Peculiarities of Art-Therapeutic Influence on Emotional Sphere of Females with Pathology of Pregnancy"}

\section{Research advisor - PhD in Psychological sciences, associate professor M.N.}

\section{Kotlyarova}

Aim: theoretical comprehension and empiric study of art-therapeutic influence on emotional sphere of females with pathology of pregnancy.

\section{Results:}

1. Art-therapeutic influence of isotherapy classes appeared to be more effective in females of the average age 26 years old with the diagnosis "edema, proteinuria and hypertensive disorders in pregnancy, deliveries and postpartum period" (O10-O16). A direct relationship between general tension of defenses (GTD) and euphoric type of psychological component of gestation dominant (PCGD) is revealed. Low parameters of GTD combine with a need for communication, denial of some frustrating circumstances evoking anxiety, or of any internal impulse. Exaggerated anxiety and irritability existing before art-therapeutic influence, disappeared after it, and a need in emotional involvement appeared.

2. Art-therapeutic influence of music therapy classes appeared to be more effective in females of the average age 28 years with the diagnosis "false labor pain after 37 full weeks of pregnancy" (O47.1). A direct relationship between the general tension of defenses (GTD) and PCGD of euphoric type was found. High parameters of GTD combine with irritability and a high level of expression of such protective mechanism of 
personality as suppression. Existence of disquieting apprehensions, forced self-restraint, control of behavior, desire to avoid conflicts present before art-therapeutic influence, disappeared after it, and active aspiration to activity and denial of any limitation of the personality appeared.

3. Art-therapeutic influence of sand therapy classes appeared to be more effective in females of the average age 25 years with the diagnosis "false labor pain before 37 full weeks of pregnancy" (O47.0). A direct relationship between GTD and of anxious type PCGD parameters was revealed. High parameters of GTD combine with impulses unacceptable for the personality, that induce anxiety and become nonconscious; they are localized outside, are assigned to other people and thus become sort of secondary. A direct relationship is identified between parameters of GTD and a desire to avoid anxiety through transition to earlier stages of libido development. A direct relationship between parameters of GTD and emotional lability manifested by frequent mood swings, enhanced excitability, irritability, insufficient self-regulation, was found. Enhanced sensitivity to environmental influences, selectivity, petulance existing before art-therapeutic influence, disappeared after it, denial of any limitations of the personality and active aspiration to activity appeared.

4. Analyzing average meanings of GTD before and after art-therapeutic influence in groups using art-therapy methods that produced a positive effect, it may be concluded that the most effective method was music therapy.

\section{Irina Yu. Kislyakova}

"Interrelation between Personality Peculiarities and Coping Strategies in Specialists of Ministry of Emergency Situations"

Research advisor - PhD in Psychological sciences, senior teacher V.V. Yakovlev 
Aim: study of peculiarities of personality and selection of coping strategies.

\section{Results:}

Effective coping-strategies are characterized by a direct relationship with altruistic, friendly, dependent and subordinate type of relations, with a personality trait of 'lability', terminal values of 'cognition', 'material security', 'health', instrumental values of 'width of views'; by feedback with 'aggravation', instrumental values of 'good manners', 'education', terminal values of 'development', 'family'.

Non-effective coping-strategies are characterized by a direct relationship with authoritarian type of interpersonal relations, sensitivity and rigidity, by feedback with terminal values of 'self-confidence', 'health', 'material security'.

A hypothesis of existence of interrelation between psychological peculiarities of personality and selection of coping strategies was confirmed.

On the basis of the results of study, a correction program was developed to improve effectiveness of coping in workers of ESM.

\section{Lidia P. Kutovaya}

"Peculiarities of Existential Attitudes in Patients with Past Stroke" Research advisor - Grand PhD in Medical sciences, professor B.Yu. Volodin

Aim: to identify peculiarities of existential attitudes in patients with past stroke.

\section{Results:}

1. Patients with a pessimistic attitude to death are to a lesser extent satisfied with their life, subjective assessment of meaningfulness of life in them is lower than in patients with an optimistic attitude to death.

2. Patients with past stroke with a pessimistic attitude to death, perceive their disease less adaptively than those with past stroke having a more optimistic attitude to death. 


\section{Pavel A. Markin}

"Study of Differences of Internal Picture of Disease in Patients with Thyrotoxicosis with and without Surgical Intervention"

Research advisor - Grand PhD in Medical sciences, associate professor D.S. Petrov

Aim: study, identification of peculiarities and comparison of the internal picture of the disease in patients with thyrotoxicosis with and without surgical intervention.

Result: results of the work confirm the hypothesis of existence of significant differences in the internal picture of the disease (IPD) in patients with thyrotoxicosis treated without surgical intervention and in patients who underwent operation for thyrotoxicosis. The hypothesis of existence of differences in the correlation structure of IPD of these groups of patients was confirmed. The result of the study was development of a correction program that took into account peculiarities of IPD of each of the two groups of patients with the aim of formation of a more adequate internal picture of the disease.

\section{Anna Ye. Matveeva}

"Study of Pathocharacterological Traits in 10th Form Pupils of High Schools and of General Academic Schools"

Research advisor - PhD in Medical sciences, associate professor V.V. Novikov

Aim: study of pathocharacterological traits in 10th form pupils of high schools and of general academic schools

\section{Results:}

1. Pupils of the $10^{\text {th }}$ form of high schools as well as pupils of the 10 th form of general academic schools are characterized by an evident intensification of pathocharacterological traits, with the absence of evident deviant behavior and social disadaptation. 
Here, the extent of the inner tension, and the extent of group dependence is more typical of teenagers studying at high school.

2. Such pathocharacterological traits as asthenia, sensitivity and negative attitude to research are more characteristic of pupils of high schools than of those of general academic schools. However, pupils of academic schools are more hypertemic.

3. In pupils of academic schools such types of disharmonic nuture as hyperprotection, excessive demands - prohibitions are more expressed, with preference of childish properties in teenagers, educational uncertainty of parents and non-development of parental feelings. But despite the fact that disharmonic types of family education are less expressed in pupils of high schools, their pathocharacterological features have more correlation relationships with types of family education.

4. Among coping strategies, pupils of high school use disadaptive coping strategies to a much more extent than pupils of academic schools.

\section{Irina N. Peregudova}

"Peculiarities of Causal Attribution and of Adaptive Capacities of Teenagers with Chronic Gastritis"

\section{Research advisor - PhD in Pedagogical sciences, associate professor I.V. Mo-}

\section{torina}

Aim: identification of peculiarities of causal attribution and of adaptive capacities of teenagers with chronic gastritis.

Results: teenagers with chronic gastritis have characteristic distinctive features of causal attribution, of parameters of personal adaptation potential, state anxiety and trait anxiety. A relationship between causal attribution and adaptation capacities in teenagers with chronic gastritis was revealed. 


\section{Vladlena P. Prilepskaya}

"Comparative Analysis of Existential Attitudes in Oncological Patients with Different Prognosis"

\section{Research advisor - Grand PhD in Medical sciences, professor B.Yu. Volodin}

Aim: comparative analysis of existential attitudes in oncological patients with breast cancer depending on prognosis of treatment.

Results: a more optimistic perception of life was noted in females treated with polychemotherapy (comparison group) than in females subject to surgical treatment (experimental group).

\section{Kristina N. Sokolova \\ "Peculiarities of Self-Comprehension of Patients with Skin Diseases" \\ Research advisor - PhD in Psychological sciences, associate professor E.K. Eremina}

Aim: Study of peculiarities of self-comprehension of patients with skin diseases and development of a model for psychocorrective work.

\section{Results:}

1. The level of reflexivity in patients with skin diseases is lower than that in healthy individuals.

2. Self-relation of patients with skin diseases differs from that of healthy individuals.

1) Patients with psoriasis are characterized by reduced level of such parameters as self-perception, self-understanding and reflexivity.

2) Patients with atopic dermatitis are characterized by reduction of self-interest, self-understanding and self-perception. 
3. Boundaries of corporeity of patients with psoriasis are characterized by insufficient formation and by damage. Boundaries of corporeity of patients with atopic dermatitis are insufficiently formed, highly permeable and damaged. In healthy individuals the boundaries are adequately formed.

In result of our experiment and of subsequent processing of the obtained data we confirmed our hypothesis stating that self-comprehension of patients with skin diseases differs from that of healthy individuals in self-relation, by lower level of reflexivity and less differentiated corporeity boundaries.

\section{Sergey A. Fedorov}

"Comparative Analysis of Cognitive Sphere of Men and Women with Alcohol Dependence"

\section{Research advisor - Grand PhD in Medical sciences, professor B. Yu. Volodin}

Aim: identification of differences in the cognitive sphere of men and women with alcohol dependence.

\section{Results:}

1. Cognitive sphere of men suffering alcoholism is more preserved than cognitive sphere of women.

2. In women with alcoholism, such cognitive processes as thinking and attention are to a larger extent frustrated than in men with alcoholism. Memory is equally disturbed in men and women.

3. Women with alcoholism show more evidently expressed disorders in the intellect than men. 


\section{Roman D. Frolov}

"Peculiarities of Compliance of Patients with Osteochondrosis"

Research advisor - PhD in Pedagogical sciences, associate professor I.V. Motorina

Aim: study of peculiarities of compliance of patients with osteochondrosis.

Results: Peculiarities of compliance of patients with osteochondrosis include expressed emotional and behavioral components, high level of anxiety, and also reduction of mood and of social activity. The studied hypothesis (about existence of peculiarities of compliance of patients with osteochondrosis) was fully confirmed. On the basis of the results of the conducted study a program was created directed at increase in compliance.

\section{Varvara V. Frolovskaya \\ "Psychological Peculiarities of Compliance of Patients with Diabetes Mellitus in Conditions of Outpatient and Inpatient Clinic"}

Research advisor - senior teacher L.N. Karashchuk

Aim: to study psychological peculiarities of compliance of patients with diabetes mellitus.

\section{Results:}

The level of compliance of patients with diabetes mellitus receiving treatment in a hospital and in those treated in a polyclinic, showed significant differences;

The level of compliance of patients with diabetes mellitus is associated with the emotional condition;

The level of compliance of patients with diabetes mellitus is associated with the type of thinking; 
The level of compliance of patients with diabetes mellitus is associated with peculiarities of interpersonal relations between a physician and a patient in the course of treatment;

The level of compliance of patients with diabetes mellitus is associated with the duration of the disease (prescription of the diagnosis).

Hypothesis of the relationship between the level of compliance of patients with diabetes mellitus and characteristics of the type of the nervous system was not confirmed in the given work and requires further study.

\section{Anna Yu. Ababilova}

"Comparative Peculiarities of Emotional Sphere in Males and Females after

\section{Stroke"}

\section{Research advisor - Grand PhD in Psychological sciences, professor D.V. So- chivko}

Aim: theoretical and empirical study of peculiarities of emotional reaction to disease in males and females after stroke.

Results: Females are more subject to anxiety, lie and depression in contrast to males. Females to a higher extent rethink stressful situation, they are more focused on unpleasant emotions, to a higher extent seek an advance or help, undertake active steps to overcome stressful situation, refer to help of God, try to find emotional and moral support, sympathy and understanding. Males are more inclined to give a humoristic shade to the situation concerning the disease, they refuse to achieve the aim directed at interaction with the stressor, they more commonly resort to alcohol or medical drugs to improve their well-being and more think about how to act in a difficult life situation.

Females are more apt to distress arising from sensation of their bodily dysfunction, to anxiety, personal inferiority, absence of interest to life, lack of motivation and loss of life energy, nervousness, panic attacks, tension and shivering, fear of certain life situa- 
tions, suspicion. Besides, females are more realistic, they try to escape from a disease to work, they actively reject thoughts about disease to the extent of denial of its consequences, they are hypochondriac, permanently tend to talk about their disease with physicians and surrounding people, exaggerate their unpleasant sensations, do not believe in recovery, are vulnerable and require special attention. Males tend to be irritated by unpleasant sensations, especially associated with pain, passively regard therapeutic procedures, require care of themselves, are alert to talks about them.

\section{Angelika E. Boyakhchyan}

\section{"Peculiarities of Cognitive Sphere of Individuals with Drug Addiction" Research advisor - Grand PhD in Medical sciences, professor B. Yu. Volodin}

Aim: study of peculiarities of cognitive sphere of individuals with drug addiction.

Results: the data of the experiment evidence reduction of cognitive sphere in individuals with drug addiction, in particular, disorders in the operational aspect of thinking, in dynamics of thinking activity and derangement of motivational component of thinking. Disorders in the process of thinking included the following components:

-Reduction in the level of generalizations

-Distortion of thinking process

•Judgement inconsistency

-Inertia of thinking processes

-Diversity

-Tangentiality

-Derailment 
-Disorder in understanding of logical associations

- Concretion of judgements

There were also found derangements of the dynamics of mental activity in patients, its easy depletion, non-uniform and uniform slowness which may indicate cognitive deficit.

Thus, we may conclude that all the above mentioned disturbances in patients with drug addiction result from cognitive deficit associated with use of narcotic substances.

\section{Olga S. Evstafieva}

"Personality Sphere and Possibility of Psychocorrection of Individuals with Drug Addiction"

\section{Research advisor - Grand PhD in Medical sciences, professor B.Yu. Volodin}

Aim: Identification of personality peculiarities of drug addicts and of possibilities of their psychocorrection in conditions of a narcotics treatment hospital.

Results: We found characteristic features of non-motivated patients, which, in comparison with those of more adaptive, motivated for rehabilitation patients, are: difficulties in expression of feelings, high state and trait anxiety, difficulties in planning of salvation to a problem. The obtained data confirm the hypothesis of adaptibility of motivated drug addicts and are of interest to a more detailed study of a relationship between a possibility to express emotions and motivation for treatment in drug addicts.

The importance of understanding dependence on psychoactive substances as a biopsychosocial disease was theoretically substantiated. From this a conclusion was made about a necessity to create a complex rehabilitation program.

A psychocorrection program was elaborated and its effectiveness was empirically assessed. 
Significant shifts were obtained in scales "Difficulties in Identification of Feelings", "Difficulties in Description of Feelings" (Toronto Alexithymia Scale), "StateTrait Anxiety inventory", "Hostility” (Bass-Perri Aggressiveness Level Questionnaire), "Responsibility Taking", "Planning of Salvation to Problem", "Escape” (Lazarus Coping Behavior Questionnaire), "Intellectualization” (Life Style Index), that is, for all parameters that were chosen by us as the main targets (topics) of the work.

\section{Karina B. Kalmurzaeva}

\section{"Peculiarities of Emotional Burnout in Individuals of Helping Professions (on an example of ESM workers and physicians)"}

\section{Research advisor - Grand PhD in Medical sciences, professor B.Yu. Volodin}

Aim: theoretical comprehension and empiric study of peculiarities of emotional burnout in workers of ESM and ambulance physicians.

Results: the most expressed level of viability and of such its components as involvement and control, is seen in firemen-rescuers. This group of people with the underlying viability, often resorts to aggressive behavior as a protective mechanism against emotional burnout. High scores in scales of inclination to implicit aggressive and hostile behavior, cynicism, aggressiveness, hostility directly correlate with the level of viability, control, involvement. According to the obtained data, high viability and all its parameters inhibit formation of symptoms of professional burnout and a symptom of reduction of professional achievements. In physicians, viability is also on a high level, but it is less expressed than in firemen-rescuers. However, physicians also resort to aggressive behavior in professional activity and in life, but in a more acceptable, socially approved form than firemen-rescuers, namely, to cynicism. With a high underlying viability, ambulance physicians have a more expressed index of reduction of personal achievements than firemen-rescuers. Physicians are more displeased with the results of their professional activity, they negatively regard themselves as professionals, with 
manifestations of self-aggression. This is confirmed by the obtained negative correlation relationship between viability and undertaking risks on the one hand, and with emotional depletion on the other hand.

\title{
Daria I. Kuzina
}

"Peculiarities of Emotional Sphere of Aged Individuals in Different Family

Situations"

Research advisor - Grand PhD in Psychological sciences, professor D.V. Sochivko

Aim: to study peculiarities of emotional sphere of aged individuals in different family situations.

\section{Results:}

1) Depression parameters are higher in aged individuals who lost contact with the family that in those who preserved contact;

2) Empathy parameters are higher among aged individuals who preserved contact with the family than in those who lost it.

Besides, such parameters of emotional sphere were studied as psychological stress and aggressiveness in aged individuals. In result, no significant changes were obtained on these scales.

\section{Daria S. Mishacheva}

“Dynamics of Suffering Operational Stress and its Relation with IndividualPsychologic Peculiarities"

\author{
Research advisor - senior teacher N.A. Belova
}

Aim: theoretical comprehension and empiric study of the problem of suffering operational stress in patients with different individual-psychological peculiarities. 
Results: a hypothesis of relationship between the dynamics of suffering operational stress and individual-psychological peculiarities was confirmed. A reliable link was found with separate parameters of comprehension of life and the level of comprehension of life on the whole, with some defense mechanisms of personality and some coping strategies. No relationship with optimism as an attributive style was revealed.

\section{Irina Yu. Nikolashkina}

"Peculiarities of Time Perspective of Women after Loss of Intrauteral Child" Research advisor - PhD in Psychological sciences, associate professor M.N.

\section{Kotlyarova}

Aim: identification of peculiarities of time perspective of women after loss of an intrauteral child.

Results: from presented results a conclusion can be made that the time perspective of women after missed miscarriage or spontaneous abortion is different from that of women after a medical abortion.

Women after missed miscarriage or spontaneous abortion are not characterized by orientation to future, their present seems fatalistic to them. It is uncharacteristic of them to make plans for future. Women after a medical abortion have a perspective for the future and set themselves aims.

Thus, it can be concluded that the hypothesis about differences in time perspectives in women with missed miscarriage or spontaneous abortion and in women after a medical abortion, is confirmed.

\section{Ekaterina V. Samokhina}

"Psychological Peculiarities of Conflict Behavior (on an example of gynecological departments of medical institutions)" 


\section{Research advisor - PhD in Psychological sciences, senior teacher V.V. Ya- kovlev}

Aim: study of psychological peculiarities of initiation of conflicts in patients of gynecological departments of medico-prophylactic institutions.

Results: a role in initiation of conflicts in patients of gynecological departments of medical institutions is played by exaltation type accentuations of their character, of selfpreoccupation, hostility, excitability; by high tolerance to uncertainty and to complicated tasks, by the external locus of control in interpersonal relations, by state and trait anxiety. It was also found that conflict behavior is influenced by such parameters as age and frequency of being on treatment in gynecological departments of medicoprophylactic institutions.

\section{Kristina V. Svirina \\ "Peculiarities of Defensiveness in Children with Bronchial Asthma" Research advisor - senior teacher M.I. Raszhiviva}

Aim: to study peculiarities of defensiveness in children with bronchial asthma.

Results: peculiarities of defensiveness in children with bronchial asthma (most expressed is denial; obstructive-dominant fixation on frustrating situation and impunitive direction of reaction are also present) differ from defensiveness of children without bronchial asthma, a relationship was found between defensiveness in children with bronchial asthma and the family education style. Families having a child with bronchial asthma, are characterized by overexpressed dominating style, where a significant role in relationship between parents and children is played by symbiontic relationship and control. It is indicative that in some cases a parent of an ill child demonstrates democratic style of family education 
Anastasia N. Sudakova

"Peculiarities of Coping Behavior in Individuals with Chronic Headache"

Research advisor - Grand PhD in Psychological sciences, professor D.V. Sochivko

Aim: to determine peculiarities of coping behavior in individuals with chronic headache.

Results: the study confirmed our hypothesis about differences between coping behavior in people with chronic headaches and in conventionally healthy individuals.

1. In test persons diagnosed with migraine, exterior control locus predominates, while in heathy individuals interior focus predominates. That is, test persons with chronic headaches tend to assign the responsibility for what is happening to external events, and are less oriented to their own forces than healthy individuals.

2. Test persons diagnosed with migraine, more commonly use such a method of coping with the stress as entering a social contact.

3. Test persons with chronic headaches more rarely use such strategies of coping behavior as assertive actions, active actions, careful actions, responsibility taking.

\section{Ekaterina I. Sukhova}

"Peculiarities of Sensory Integration in Children with Severe Degree of Mental Retardation"

\section{Research advisor - senior teacher L.N. Karashchuk.}

Aim: study of peculiarities of sensory integration in children with a severe degree of mental retardation.

Results: In result of conducted study it was found that children with different intellectual level have different peculiarities in disorders of sensory integration. 
Besides, it could also be seen that the intellectual level does not influence disorders in the processing of sensory information, but causes only small changes in audial, visual and vestibular dysfunction.

It was revealed by us that vestibular and audial dysfunctions and dysfunctions of oral signals influence behavioral and thinking peculiarities, but the suggestion about the influence of proprioceptive dysfunction was denied.

\section{Ekaterina V. Tomashova}

"Peculiarities of Perception of Family Relations and Self-Relation of Teenagers with Bronchial Asthma"

\section{Research advisor - senior teacher N.A. Belova}

Aim: to study peculiarities of perception of family relations and self-relation of teenagers with bronchial asthma.

Results: such components of self-relation as self-management, self-confidence, openness, self-accusation and mirror Ego are associated with directivity, hostility and autonomy of parents. There exists a direct relationship between the level of self-esteem of teenagers with bronchial asthma, and family cohesion and adaptation. It was also shown that there exist significant differences between two groups of test persons in perception of children-parent relationships according to scales "Proneness to Conflict", "Encouragement" in relation to mother, and "Control", "Authoritarianism". "Uncertainty of Parent" in relation to father.

\section{Ksenia A. Tsepeleva}

"Individual-Personal Peculiarities of Women with Disorders in Adaptation" Research advisor - assistant L.E. Talanova 
Aim: identification of individual-personal peculiarities of female patients diagnosed with disorders in adaptation, in comparison with females without this diagnosis with a similar high stress level.

Results: A suggestion about existence of statistically reliable differences in peculiarities of personality between the studied groups of females (with and without diagnosis 'disorders in adaptation'), is confirmed. The following personality characteristics of women diagnosed with adaptation disorders were found: evident anxiety in interrelations with close people, evident tendency to avoid close relations, reduced subjective evaluation of physical component of the quality of life, self-accusation position, insufficiency of self-perception and of self-respect.

\section{Victoria A. Abrashina \\ "Self Image as Mother in the Structure of Ego-Concept of Pregnant Females" Research advisor - PhD in Psychological sciences I.S. Isaeva}

Aim: study of peculiarities of creation of self image as a mother in women with natural pregnancy and in women with pregnancy in result of use of assisted reproductive technologies (extracorporal fertilization, ECF).

Results: The conducted research showed that females with natural pregnancy are characterized by optimal type of relations, impulsiveness, emotional coldness, family conflicts, which is supposedly associated with destructive motives of preservation of pregnancy when pregnancy is a subjective sensation of limitation of freedom and a way of keeping the husband in the family. Females with natural pregnancy are characterized by disregard of the style of going through pregnancy and by conflicts with pregnancy or with the maternity situation. This group is oriented on the past life including aims and significant events which are not transferred to the present and future. Besides, they have characteristic positive relations between Ego-real and Ego-ideal, adequate self-esteem, 
and negative relation between these components and reduced self-esteem, which are not noted in group with ECF.

The conducted study showed that females participating in ECF program, were characterized by euphoric type of relations, anxiety, distrust of themselves which is presumably associated with subjective relation to material problems and correspondence to social expectations. This group is characterized by a correspondence to a self image of a strong personality who makes the life according to the set aims with understanding of its sense. Besides, they have a characteristic relationship between Ego-real and Ego-ideal, adequate self-esteem with a tendency to over-esteem. Characteristic of this group is a favorable maternity situation, adequate style of going through pregnancy and acceptance of it.

\section{Maria N. Barsukova}

"Correction of Ego-Concept of Individuals with Special Demands Using Method of Theatre Therapy"

\section{Research advisor - PhD in Psychological sciences V.V. Yakovlev}

Aim: identification of peculiarities of Ego-concept of individuals with specific demands and their correction by a method of theatre therapy.

Results: disorders in the valuation component of Ego-concept of people with special demands identified in the stage of psychodiagnostic study, confirm the hypothesis about a disharmonic character of Ego-concept of people with special demands.

Statistical analysis of the obtained results shows consistency of the second hypothesis directed at confirmation of the efficacy of the method of theatre therapy within the frames of correction of Ego-concept of people with special demands. 


\section{Maria A. Igoshina}

"Peculiarities of Internal Picture of Disease of Patients with Different Stages of Chronic Renal Failure"

\section{Research advisor - PhD in Psychological sciences, associate professor M.N.} Kotlyarova

Aim: identification and study of specificity of the internal picture of the disease of patients with different stages of renal failure.

Results: characteristics of sensual, emotional and motivational levels of the internal picture of the disease which possesses certain specificity in each stage of the disease. Besides, correlations were found between TATD scales and Schmischek questionnaire which permits to suggest existence of relationship between selection of the attitude towards the disease and personality traits.

\section{Daria N. Kayuchkina \\ "Analysis of Peculiarities of Family Education and Personal Characteristics of Children and Teenagers with Bronchial Asthma" Research advisor - PhD in Psychological sciences, associate professor N.V. Yakovleva}

Aim: theoretical comprehension and study of interrelations between peculiarities of family education and personal characteristics of children and teenagers with bronchial asthma.

Results: no specific significant differences were found between personal characteristics, but the dominating style of family education in relation to children and teenagers with the given psychosomatic disease is overprotection, which was in principle suggested at the beginning of study. 
Spearman's rank order correlation between peculiarities of family education and personal characteristics of teenagers with bronchial asthma revealed a positive relationship between projection of self undesired qualities on a child and hostility, between overprotection and trait anxiety; and a negative relationship between overprotection and trait anxiety, maximal prohibitions and friendliness, maximal sanctions and general aggressiveness. Correlation of peculiarities of family education and personal characteristics of children with bronchial asthma gave only negative relationships: between overprotection and obstructive-dominant type of reaction, and between uncertainty of education and ego-protective type of reaction.

Factorial analysis revealed 4 most significant factors in teenagers with bronchial asthma.

\section{Anastasia S. Koslova}

"Peculiarities of Emotional-Volition Sphere of Individuals with Alcoholism" Research advisor - Grand PhD in Psychological sciences, professor D.V. Sochivko

Aim: study of peculiarities of emotional-volition sphere in individuals with alcoholism.

Results: emotional-volition sphere in individuals with alcoholism possesses certain peculiarities and is different in males and females with alcoholism.

\section{Yana S. Kokareva}

"Coping with Stress and Internal Picture of Disease of Patients with Ischemic Heart Disease of Different Duration"

Research advisor - Grand PhD in Medical sciences, associate professor D.S. Petrov 
Aim: study of peculiarities of internal picture of the disease (IPD) and methods of coping behavior (MCB) in patients with IHD of different duration.

Results: in the course of study statistical differences were revealed in the types of IPD, in particular, in anosognosic type. The given form of IPD predominates in patients with duration of IHD up to 1 year. Such parameters can be explained from the point of view of the form and time of the disease, since in the first group of patients the disease was in the acute period characterized by a sudden unexpected beginning, and lack of information of the disease and of one's condition did not permit to rapidly adapt and get used to the idea of disease.

A positive correlation was noted of different types of IPD with the state and trait anxiety, with Zung Self-Rating Depression Scale and with control locus, both external and internal. On the contrary, not a single method of coping behavior correlated with Zung Self-Rating Depression Scale, although the scale itself correlates with external control locus. Besides, the external control locus itself correlates with state and trait anxiety. Such tendency was traced in both sampling groups.

\section{Anton S. Krysin \\ "Study of Emotional Intellect and Conflict Behavior of Regularly Hospitalized Aged Patients" \\ Research advisor - PhD in Medical sciences V.V. Novikov}

Aim: study of emotional intellect and conflict behavior of regularly hospitalized aged patients.

Results: Regularly hospitalized aged patients are more inclined to the feeling of injustice, inferiority and dissatisfaction of demands which leads to hostility. They also lack independence which leads to helplessness and sensitivity. In a conflict they tend to find a compromise or sacrifice their own interests for those of another individual. They possess a more evident ability to identify and express both their own and other individu- 
als' emotions of different strength and modality. All the mentioned features are absent in aged individuals who do not undergo regular hospitalizations. Thus, the first hypothesis stating that expressiveness of individual-psychologic features evidencing enhanced proneness to conflicts is higher in regularly hospitalized aged patients, was not confirmed.

2. Regularly hospitalized aged patients have more evident tendencies to the following forms of behavior in conflict situations: compromise, avoidance and adaptation Such forms as avoidance and adaptation are associated with attention to interests of other individuals involved into the conflict. However, a compromise stands apart of this group of tendencies and is characterized as a medium form in the continuum of direction of attention of an individual in conflict situation. Thus, the hypothesis suggesting that regularly hospitalized aged patients are more characterized by attention to the interests of other people involved into a conflict as compared to aged individuals who do not undergo regular hospitalization, was partially confirmed.

3. The third hypothesis suggesting that expressiveness of components of emotional intellect in regularly hospitalized aged patients has certain specificity, was confirmed, since among the components of emotional intellect in this category of individuals most expressed is the ability to exactly identify and express emotions and demands associated with these sensations, and also the ability to identify the emotion in physical conditions, sensations and thoughts.

\section{Nadezhda A. Mayorova}

"Internal Picture of Disease of Patients with Pancreatitis"

Research advisor - PhD in Psychological sciences, associate professor N.V. Yakovleva

Aim: study of peculiarities of internal picture of disease of patients with pancreatitis. 
Results: in the course of empirical experiment conducted on a sample of patients with gastritis and pancreatitis, peculiarities of the internal picture of the disease of each patient were described. In turn, peculiarities of the internal picture of the disease of patients with pancreatitis were identified, and the harmonicity of the picture was evaluated. Data of reliable differences in emotional, motivational and behavioral components of the internal picture of the disease were identified. These differences were not cardinal, since patients with gastritis and those with pancreatitis belong to the psychological type of gastrointestinal diseases.

Evaluation of the internal picture of the disease of patients with pancreatitis of different etiology also showed some peculiarities. Thus, reliable differences in cognitive, motivational and behavioral components of the disease were found. The obtained data indicate a non-harmonic image of the disease.

The found peculiarities permit to develop a correction program for effective adaptation of patients, elimination of symptoms of anxiety and depression and formation of a harmonic attitude towards the disease.

It follows from the above that the general hypothesis about the existence of peculiarities of the internal picture of the disease in patients with pancreatitis was confirmed. A specific hypothesis about differences in the internal picture of the disease in patients with pancreatitis determined by different etiology and character of the disease, was also confirmed.

\author{
Ksenia V. Maysak
}

"Interrelation between Level of Emotional Burnout and Professional Deformation in Military Pilots"

Research advisor - Grand PhD in Medical sciences, professor B.Yu. Volodin 
Aim: study of syndrome of emotional burnout and professional deformation in the structure of personality peculiarities of military servicemen of Air Military Forces of the RF.

Results: In result of the work the data were obtained concerning both the theoretical and practical aspects of the problem. In the theoretical aspect the main approaches were considered that explain initiation and development of emotional burnout and professional deformation in military pilots. Besides, the main determinants were considered that provide an organism with an ability to resist stress and provide the adaptive level of functioning with the result of achievement of emotional and personal well-being.

In the practical part of the experiment, manifestations of certain components of professional deformation in the form of syndrome of emotional burnout (SEB) were studied. The following results were obtained: components of professional deformation in pilots with emotional burnout were more expressed than in military pilots without this syndrome. Besides, we determined and statistically confirmed the existence of interrelation between these two components in the group of pilots with syndrome of emotional burnout. Pilots with SEB show higher parameters of aggressiveness and neuro-psychic instability. Besides, we determined and statistically confirmed the existence of interrelation between these two components which is manifested, in particular, in enhanced level of aggression and predomination of non-adaptive copingstrategies.

Natalia I. Mashnikova

"Peculiarities of Emotional Condition in Postoperative Period of Patients

Hospitalized after Road Accidents and for Urgent Indications"

Research advisor - senior teacher N.A. Belova

Aim: to study peculiarities of condition in postoperative period of patients hospitalized after road accidents and for urgent indications 
Results: In result of the study it was found that a road accident may cause a specific emotional condition characterized by presence of symptoms of anxiety and depression, PTSD syndrome and also by a specific coping behavior. Besides, there also exists a relationship between predominating symptoms in the structure of suffering a psychotraumatic situation and the type of coping behavior.

\section{Anastasia A. Nikolaeva}

"Study of Personal Peculiarities of Patients of Surgical Profile and of Evidence of Psychopathological Manifestations in Different Stages of Treatment" Research advisor - senior teacher N.A. Belova

Aim: study of personal peculiarities of patients of a surgical profile and of expressiveness of psychopathological manifestations in different stages of treatment.

Results: Parameters of expressiveness of psychopathological manifestations in the postoperative period were higher than in preoperative period. This is the ground for conclusion about worsening of condition of patients in this stage of treatment.

Besides, a relationship was found between personal peculiarities of patients and dynamics of expressiveness of psychopathological manifestations.

Tatyana Ye. Renner

"Characteristics of Quality of Life of Patients with Debilitating Somatic Diseases with Vital Threat (on example of chronic renal failure and type I diabetes mellitus)"

Research advisor - Grand PhD in Medical sciences, associate professor D.S. Petrov

Aim: theoretical comprehension and empiric study of peculiarities of the healthdetermined quality of life of patients with two debilitating somatic diseases with a vital 
threat: type I diabetes mellitus with administered insulin therapy and terminal stage of chronic renal failure.

Results: In result, the characteristics of the quality of life of patients with two debilitating somatic diseases were obtained.

The proposed hypotheses were confirmed.

The parameter of physical component of the quality of life was significantly lower in patients with a need for hemodialysis, with this, no differences were detected with patients with diabetes mellitus in parameters of a psychological component - average meanings were lower in both samples as compared to the population.

Correlation structure had differences - here, coincidences exist in the interrelation of viability parameters and health assessment in both samples.

\section{Vladislav V. Tursunov}

"Peculiarities of Cognitive Processes in Individuals after Craniocerebral Inju-

$$
\text { ry" }
$$

\section{Research advisor - senior teacher N.A. Belova}

Aim: to study peculiarities of cognitive processes in individuals after craniocerebral injury.

Results: It was found that in patients after craniocerebral trauma, such aspects of cognitive processes as perception of faces, differentiation of faces, memorization and recognition of faces were reliably lower than in healthy test persons. With this, resting on the data of questionnaires, it can be concluded that patients subjectively had no problems with cognition of faces before the trauma, and subjectively perceived the quality of life at the same level as healthy test persons. Non-specific disorders in attention may also be indicated by interrelation between the average time of implementation of Schulte Table and speed of selection of answers in Cambridge Face Memory Test which is associated with the work of the first block of the brain. 


\section{Daria A. Shishkova}

\section{"Cognitive Sphere of Personality of Individuals Using Spices"}

Research advisor - PhD in Medical sciences, associate professor A.K. Afonina

Aim: to discuss peculiarities of cognitive control in individuals using synthetic cannabinoids for optimization of targets for action in medico-psychological rehabilitation of the given category of individuals.

Results: individuals taking synthetic cannabinoids, exhibit impairment in such processes as attention, memory, thinking, that is, processes of cognitive sphere. This is assigned to the detrimental influence of narcotic drugs on the whole cognitive sphere of a human personality. Only a low percent of test objects demonstrated a high level of concentration, consideration of a problem in perspective, positive reconsideration of the problem and re-focusing on planning, which are components of cognitive control.

Insignificant differences in planning level inside the groups can be attributed to the fact that a high planning level in individuals taking synthetic cannabinoids is due to inclusion of rehabilitation and psychotherapeutic interventions which naturally activate planning.

Further it seems possible to apply the obtained data to practice with subsequent making conclusions about effectivity. To develop new exercises taking into account functioning of cognitive control in individuals taking synthetic cannabinoids. Besides, it is necessary to study peculiarities of copings in this group of individuals that are directed at emotional regulation. In this way, the cognitive and emotional aspects will be studied which will lead us to correct construction of programs for change in behavior.

\section{Olesya V. Shukalovskaya}

"Age-Related Peculiarities of Self-Comprehension in Women with Dissociation Disorder" 


\section{Research advisor - Grand PhD in Psychological sciences, professor D.V. So- chivko}

Aim: to study peculiarities of self-relation and self-actualization in women with dissociation disorder.

Results: a relationship has been established between elements of self-relation and self-actualization in women with dissociation disorder. Besides, in women of different age groups, the expressiveness of the elements of self-relation and self-comprehension showed significant differences. Peculiarities of self-relation and self-actualization are different in females with dissociation disorder in the period of early youth and of middle age.

Дата поступления / Paper received: 20.02.2019

Дата принятия в печать / Paper accpeted: 20.03.2019

\section{ССЫЛКА ДЛЯ ЦИТИРОВАНИЯ:}

Аннотации выпускных квалификационных работ студентов факультета клинической психологии 2019 года [Электронный ресурс] // Личность в меняющемся мире: здоровье, адаптация, развитие: сетевой журн. 2019. Т.7. №1 (24). Режим доступа: http://humjournal.rzgmu.ru/art\&id=369 (дата обращения: чч.мм.гггг).

\section{REFERENCE FOR CITING:}

Annotacii vypusknyh kvalifikacionnyh rabot studentov fakul"teta klinicheskoj psihologii 2019 goda [Annotations of final qualifying works of students of the Faculty of Clinical Psychology in 2019] [Electronic resource] // Lichnost' v menyayushchemsya mire: zdorov'ye, adaptatsiya, razvitiye: setevoyzhurnal [Personality in a changing world: health, adaptation, development: network journal]. 2019. V.7. №1 (24). Access mode: http://humjournal.rzgmu.ru/art\&id=369 (date of reference: hh.mm.yyyy). 
Electronic scientific journal

« PERSONALITY IN A CHANGING WORLD: HEALTH, ADAPTATION, DEVELOPMENT»

www.humjournal.rzgmu.ru / E-mail: humjournal@rzgmu.ru 
Electronic scientific journal

« PERSONALITY IN A CHANGING WORLD: HEALTH, ADAPTATION, DEVELOPMENT»

www.humjournal.rzgmu.ru / E-mail: humjournal@rzgmu.ru 
Electronic scientific journal

« PERSONALITY IN A CHANGING WORLD: HEALTH, ADAPTATION, DEVELOPMENT»

www.humjournal.rzgmu.ru / E-mail: humjournal@rzgmu.ru 